\title{
Effect of CPAP on Blood Pressure in Patients with Obstructive Sleep Apnea and Resistant Hypertension
}

\author{
Commentary on Martínez-García M, Capote F, Campos-Rodríguez F, et. al. Effect of CPAP on \\ blood pressure in patients with obstructive sleep apnea and resistant hypertension: the HIPARCO \\ randomized clinical trial. JAMA 2013;310:2407-2415. \\ Shirin Shafazand, M.D., M.S., F.A.A.S.M.'; Sanjay R. Patel, M.D., M.S., F.A.A.S.M² \\ ${ }^{1}$ University of Miami, Miami, FL; ${ }^{2}$ Harvard Medical School, Boston, MA
}

\section{SUMMARY OF MARTÍNEZ-GARCÍA ET AL.}

\section{Question}

In individuals with resistant hypertension and obstructive sleep apnea (OSA), does the 12 week use of continuous positive airway pressure (CPAP) therapy vs. control (no CPAP) improve the 24-hour ambulatory mean blood pressure?

\section{Methods}

\section{Design}

Open label, multi-center, randomized, controlled trial; clinicaltrials.gov Identifier: NCT00616265.

\section{Allocation}

Randomization was conducted by site investigator, using specific software designed for the study that randomly assigned group allocation. Allocation was stratified by site. The randomization sequence was concealed by the software.

\section{Blinding}

The investigators and participants were not blinded to study arm assignment. The primary outcome measurement was blinded.

\section{Follow-up period}

3 months.

\section{Setting}

Participants were consecutively recruited from the Hypertension Clinical Units of 24 teaching hospitals in Spain.

\section{Subjects}

194 patients were randomly assigned to receive $\operatorname{CPAP}(n=98)$ or no CPAP (control; $\mathrm{n}=96$ ). The mean age of participants was $56.0 \pm 9.5$ years, $69 \%$ were male, mean BMI was $34.1 \pm 5.4$ and the mean AHI was $40.4 \pm 18.9$. The mean number of years since diagnosis of resistant hypertension was $12.8 \pm 8.6$ and mean number of systemic anti-hypertensive medications used was $3.8 \pm 0.9$.
Inclusion Criteria: 1) primary resistant hypertension defined on 24-hour ambulatory blood pressure monitoring (24-ABPM) as blood pressure that remained above goal (i.e., average SBP $\geq 130 \mathrm{~mm} \mathrm{Hg}$, average DBP $\geq 80 \mathrm{~mm} \mathrm{Hg}$, or both) in spite of concurrent use of at least 3 antihypertensive medication agents prescribed at doses that provide optimal benefit, 2) age 18 to 75 years, 3) OSA, diagnosed by attended respiratory polygraphy (no EEG monitoring), defined as AHI of 15 or higher, 4) informed consent to participate.

Exclusion Criteria: 1) Secondary causes of resistant hypertension, 2) pregnancy, 3) disabling hypersomnia requiring urgent treatment (defined as an Epworth Sleepiness Scale $\geq 18$ ), 4 ) current use of CPAP, 5) poor adherence with antihypertensive treatment, 6) long-term treatment with oral corticosteroids or nonsteroidal anti-inflammatory drugs, 7) renal insufficiency (creatinine $\geq 1.5 \mathrm{mg} / \mathrm{dL}$ ), 8) a cardiovascular event in the month prior to the inclusion in the study, and 9) the regular use of sedatives, antipsychotics, and alcohol.

\section{Intervention}

Patients meeting eligibility criteria were randomized to either CPAP or no CPAP (control) for 12 weeks. Auto-titrating CPAP was used in the sleep laboratory within a period of less than 15 days after the diagnostic study to obtain a fixed CPAP pressure value (judged to be optimal by 2 blinded sleep experts). The fixed CPAP pressure was used for the remainder of the study. All patients were scheduled for follow-up 2 weeks after randomization and, subsequently, at 4, 8, and 12 weeks. During the follow-up visits, adherence to CPAP and anti-hypertensive medications were documented. At 12 weeks, a repeat 24-hour ABPM test was conducted in all patients.

\section{Outcomes}

The primary outcome was the change in the 24-hour ambulatory mean blood pressure from baseline to 12 weeks. Secondary outcome measures included changes in diurnal and nocturnal SBP, DBP, and changes in nocturnal blood pressure patterns.

The sample size (70 per group) was calculated to detect a reduction of $4 \mathrm{~mm} \mathrm{Hg}$ or more in 24-hour mean blood pressure, 
assuming a pooled standard deviation of 8.7 a Type I error of $5 \%$, and a statistical power of $80 \%$.

\section{Patient follow-up}

Intention to treat analysis with replacement of missing values by multiple imputations; 87 of $98(88.7 \%)$ completed follow-up in CPAP arm, 87 of 96 (90.6\%) completed follow-up in control arm.

\section{Main results}

The CPAP group achieved a statistically significant greater decrease in 24-hour mean blood pressure $(3.1 \mathrm{~mm} \mathrm{Hg}$ [95\% CI, 0.6 to 5.6]; $\mathrm{p}=0.02)$ and 24-hour DBP $(3.2 \mathrm{~mm} \mathrm{Hg}[95 \%$ CI, 1.0 to 5.4]; $\mathrm{p}=0.005)$, but not 24-hour SBP $(3.1 \mathrm{~mm} \mathrm{Hg}$ [ $95 \% \mathrm{CI},-0.6$ to 6.7$] ; \mathrm{p}=0.10$ ) compared to the control group. The percentage of patients displaying a nocturnal blood pressure dipper pattern at the 12-week follow-up was greater in the CPAP group than in the control group (35.9\% CPAP vs. $21.6 \%$ control; $p=0.02$ ). Additionally, fewer patients in the CPAP group displayed a nocturnal riser pattern at the end of the study compared to the control group (adjusted OR, 0.45; $\mathrm{p}=0.03$ ).

There were no differences in the percentage of patients reaching a normotensive range in the 24-hour mean blood pressure $(<130 / 80 \mathrm{~mm} \mathrm{Hg})$ between the CPAP group and control group $(18.4 \%$ CPAP vs. $13.8 \%$ control; $\mathrm{p}=0.41)$.

The average CPAP use was $5 \pm 1.9$ hours per night, with 71 patients (72.4\%) using it at least 4 hours per night. When comparing only those patients with complete data and 4 hours or greater average CPAP use versus controls (per protocol analysis), patients in the CPAP group showed a statistically significant decrease in 24-hour mean blood pressure of $4.4 \mathrm{~mm}$ $\mathrm{Hg}(95 \% \mathrm{CI}, 1.8$ to 7$), \mathrm{p}=0.001$; SBP, $4.9 \mathrm{~mm} \mathrm{Hg}(95 \% \mathrm{CI}$, 1.2 to 8.6$), \mathrm{p}=0.01$; and DBP, $4.1 \mathrm{~mm} \mathrm{Hg}(95 \% \mathrm{CI}, 1.9$ to $6.4), p<0.001$. This difference was more evident during the night, with a decrease of $7.1 \mathrm{~mm} \mathrm{Hg}(\mathrm{p}=0.003)$ in nocturnal SBP and $4.1 \mathrm{~mm} \mathrm{Hg}(\mathrm{p}=0.003)$ in nocturnal DBP. Moreover a small positive linear correlation between hours of CPAP use and improvement in mean blood pressure was noted $(r=0.29$, $p=0.006$ ); with an improvement of mean blood pressure of 1.3 $\mathrm{mm} \mathrm{Hg}$ for each additional hour of CPAP use.

\section{Conclusion}

In adults with moderate to severe OSA and resistant hypertension despite optimal anti-hypertensive therapy, treatment of OSA with CPAP improved the mean 24 hour blood pressure after 12 weeks of therapy.

Sources of funding: The study received a grant from PhilipsRespironics, Sociedad Española de Neumología, Instituto de Salud Carlos III, and Sociedad Valenciana de Neumología.

For correspondence: Miguel-Ángel Martínez-García, M.D., Ph.D.Email: mianmartinezgarcia@gmail.com.

\section{COMMENTARY ON MARTÍNEZ-GARCÍA ET AL.}

A strong body of research including both animal models and observational longitudinal studies implicates obstructive sleep apnea (OSA) as a causal risk factor for hypertension. ${ }^{1,2}$
Randomized trials have demonstrated consistently that OSA therapy with CPAP lowers blood pressure by $2-3 \mathrm{~mm} \mathrm{Hg} .^{3}$ This effect is clinically significant in that it would be expected to reduce cardiovascular events by $5-10 \%,{ }^{4}$ but nevertheless, underwhelming when compared to the larger effects of antihypertensive medications. Many have suggested that these results may underestimate the true potential impact of CPAP because previous trials included patients with normal or only mildly elevated blood pressures, an inadequate severity of OSA, or who had poor adherence to CPAP. Small studies suggest the effect of OSA therapy may be much greater in patients with resistant hypertension. ${ }^{5}$ If this were the case, this subgroup might benefit from routine OSA screening and treatment, particularly because OSA is highly prevalent in this population. ${ }^{6}$

The HIPARCO study represents the first high-quality clinical trial to specifically assess to what extent CPAP reduces blood pressure in patients with OSA and comorbid resistant hypertension. The investigators confirm the high prevalence of OSA in a resistant hypertension population-roughly $194 / 218$ or $89 \%$. The inclusion and exclusion criteria clearly identified a population with suboptimal blood pressure control despite 3 or more antihypertensive medications - a group most in need for novel blood pressure reduction strategies. The investigators carefully excluded the most common cause of resistant hypertension, medical noncompliance, to provide a homogenous population most likely to benefit from OSA treatment. The conservative definition of OSA, an apnea hypopnea index (AHI) $>15$ based on a hypopnea definition requiring a $4 \%$ desaturation, ensured "real" disease, particularly since the mean AHI was 40.4. One minor criticism lies in determination of the effective CPAP pressure. The mean residual AHI was $4.1 \pm 3.8$ suggesting a number of patients may have had residual disease (particularly, given the strict rules for hypopnea scoring). The mean CPAP pressure of $8.5 \mathrm{~cm} \mathrm{H}_{2} \mathrm{O}$ seems low for a population of severe apneics, further raising concern of suboptimal treatment. Nevertheless, the mean CPAP compliance obtained, $5.0 \mathrm{~h} / \mathrm{night}$, is impressive considering this population was not recruited based on OSA symptoms. The outcome measure, 24-hour ambulatory blood pressure, is appropriately chosen to maximize sensitivity to the impact of OSA therapy. Some might criticize the lack of blinding to treatment allocation. However, there is little evidence of a placebo effect on blood pressure in prior OSA trials, so the use of sham CPAP seems unnecessary. Finally, the authors are to be commended for a fairly low dropout rate and use of multiple imputation to minimize bias from missing data.

The primary finding of the study, a $3.1 \mathrm{~mm} \mathrm{Hg}$ reduction in mean blood pressure in the intent-to-treat analysis, is remarkably similar to prior trials and as such, simultaneously reassuring and disappointing. It is reassuring that OSA therapy has an additive effect on blood pressure control even when superimposed on to 3-4 antihypertensive medications. This confirms an earlier study of the additive effect of CPAP and valsartan. ${ }^{7}$ For a population that is failing standard antihypertensive therapy, CPAP may provide a much better risk-benefit profile than a 4th or 5th line antihypertensive agent. Comparative effectiveness studies testing this hypothesis would clarify the role of CPAP in this setting. Despite the statistically significant reduction in blood pressure, the results are disappointing in that most sleep experts would have predicted a greater benefit in this popu- 
lation. Certainly an 8-10 $\mathrm{mm} \mathrm{Hg}$ benefit would have made it much easier to convince our hypertension colleagues to start routinely screening and treating OSA.

In addition to lowering mean blood pressure, the investigators found CPAP can alter the blood pressure profile to produce a normal nocturnal dipping pattern. While non-dipping has been shown to be an independent risk factor for cardiovascular disease ${ }^{8}$ there are no data on whether modifying dipping status alters cardiovascular risk. As a result, it is unclear whether the change in blood pressure profile has clinical significance beyond the reduction in mean blood pressure.

So, is this the final answer then-CPAP is never going to reduce blood pressure more than $3 \mathrm{~mm} \mathrm{Hg}$ ? Some have suggested that a greater effect may occur over a longer period of time to allow for vascular remodeling. However, there is no increase in CPAP effect on office blood pressure going from 3 months to 12 months. ${ }^{9}$ The linear relationship of greater CPAP use with greater blood pressure effect, also seen in prior studies, ${ }^{9,10}$ suggests the key to gaining a greater effect from OSA therapy may lie in developing techniques to enhance CPAP adherence or developing more tolerable treatments for OSA. Further investments in this area are clearly needed.

There also may exist subgroups that are more sensitive to the hypertensive effects of OSA and therefore to the anti-hypertensive effects of CPAP. These may relate to specific hypertensive pathways (e.g., hyperaldosteronism) or specific genetic backgrounds. For example, one study suggests African-Americans, a group at particularly high risk for hypertension and less responsive to standard antihypertensive medications, may have a greater blood pressure response to CPAP. ${ }^{11}$

In the end, however, despite all the interest in blood pressure, we must remember that blood pressure is merely a surrogate outcome. What our patients really care about and the question we need to strive to answer directly is whether CPAP therapy reduces cardiovascular events and mortality.

\section{CITATION}

Shafazand S, Patel SR. Effect of CPAP on blood pressure in patients with obstructive sleep apnea and resistant hypertension. J Clin Sleep Med 2014;10(3):341-343.

\section{REFERENCES}

1. Brooks D, Horner RL, Kozar LF, Render-Teixeira CL, Phillipson EA. Obstructive sleep apnea as a cause of systemic hypertension. Evidence from a canine model. J Clin Invest 1997:99:106-9.

2. Peppard PE, Young T, Palta M, Skatrud J. Prospective study of the association between sleep-disordered breathing and hypertension. N Engl J Med 2000;342:1378-84

3. Fava C, Dorigoni S, Dalle Vedove $F$, et al. Effect of continuous positive airway pressure (CPAP) on blood pressure in patients with obstructive sleep apneal hypopnea. A systematic review and meta-Analysis. Chest 2013 Sep 26. [Epub ahead of print].

4. Lewington S, Clarke R, Qizilbash N, Peto R, Collins R. Age-specific relevance of usual blood pressure to vascular mortality: a meta-analysis of individual data for one million adults in 61 prospective studies. Lancet 2002;360:1903-13.

5. Logan AG, Tkacova R, Perlikowski SM, et al. Refractory hypertension and sleep apnoea: effect of CPAP on blood pressure and baroreflex. Eur Respir $J$ 2003;21:241-7.

6. Logan AG, Perlikowski SM, Mente A, et al. High prevalence of unrecognized sleep apnoea in drug-resistant hypertension. J Hypertens 2001;19:2271-7.

7. Pepin JL, Tamisier R, Barone-Rochette G, Launois SH, Levy P, Baguet JP. Comparison of continuous positive airway pressure and valsartan in hypertensive patients with sleep apnea. Am J Respir Crit Care Med 2010;182:954-60.

8. Routledge FS, McFetridge-Durdle JA, Dean CR. Night-time blood pressure patterns and target organ damage: a review. Can J Cardiol 2007;23:132-8.

9. Barbe F, Duran-Cantolla J, Capote F, et al. Long-term effect of continuous positive airway pressure in hypertensive patients with sleep apnea. Am J Respir Crit Care Med 2010;181:718-26.

10. Haentjens $P$, Van Meerhaeghe A, Moscariello A, et al. The impact of continuous positive airway pressure on blood pressure in patients with obstructive sleep apnea syndrome: evidence from a meta-analysis of placebo-controlled randomized trials. Arch Intern Med 2007;167:757-64.

11. Prasad B, Carley DW, Krishnan JA, Weaver TE, Weaver FM. Effects of positive airway pressure treatment on clinical measures of hypertension and type 2 diabetes. J Clin Sleep Med 2012;8:481-7.

\section{SUBMISSION \& CORRESPONDENCE INFORMATION}

\section{Submitted for publication January, 2014}

Accepted for publication January, 2014

Address correspondence to: Shirin Shafazand, M.D., M.S., University of Miami, Division of Pulmonary, Critical Care and Sleep Medicine, PO Box 016960 (D60), Miami, FL, 33101; Tel: (305) 243-7838; E-mail: sshafazand@med.miami.edu

\section{DISCLOSURE STATEMENT}

The authors have indicated no financial conflicts of interest. 